\title{
PLANEJAMENTO ESTRATÉGICO COMO TECNOLOGIA SOCIAL PARA A EFICÁCIA DA GESTÃO PÚBLICA: UM ESTUDO DE CASO - PREFEITURA DE ITAJAÍ - SC
}

\author{
Alcides Volpato ${ }^{1}$ \\ ORCID: 0000-0001-9712-894 \\ Evandro Luiz PASA ${ }^{2}$ \\ ORCID: 0000-0002-5945-8812 \\ RAQUEL GASTALDi ${ }^{3}$ \\ ORCID: 0000-0002-5566-3835
}

Resumo: O presente artigo apresenta e analisa a Metodologia de elaboração de Planejamento Estratégico de uma cidade e sua importância frente ao atual cenário político brasileiro. Apresenta também as análises dos processos aplicados e os resultados de uma construção multi - saberes - setores - gerações com mais de 3.000 pessoas envolvidas, resultando em um mapa estratégico onde foram definidos objetivos estratégicos de áreas distintas e que originaram ações estratégicas, com vistas a construção, em duas décadas, de uma cidade inteligente, sustentável e com justiça social.

Palavras-chave: Planejamento Estratégico, Políticas Públicas, Gestão Pública.

1 Coordenador Executivo do Planejamento Estratégico do Município de Itajaí, Mestrando em Gestão de Políticas Públicas da Universidade do Vale do Itajaí (Univali). E-mail: (volpato.alcides@itajai. sc.gov.br).

2 Gerente de Relações Públicas do Planejamento Estratégico do Município de Itajaí, Bacharel em Comunicação Social, Especialista em Comunicação, Publicidade e Propaganda. E-mail: (evandro. pasa@itajai.sc.gov.br).

3 Professora e Pesquisadora da Universidade do Vale do Itajaí (Univali), Mestre em Psicolinguística (UFSC) e co-coordenadora da construção do PEMI 2040.E-mail: (raquel@univali.br). 


\title{
STRATEGIC PLANNING AS SOCIAL TECHNOLOGY FOR THE EFFECTIVENESS OF PUBLIC MANAGEMENT: \\ A CASE STUDY - ITAJAÍ PREFECTURE - SCT
}

\begin{abstract}
This article presents and analyzes the Methodology for the elaboration of a city's Strategic Planning and its importance in the face of the current Brazilian political scenario. It also Presents the analyses of the applied processes and the results of a multi-knowledge construction - sectors - generations with more than 3.000 people involved, resulting in a strategic map where objectives were defined Strategic actions, with a view to building, in two decades, a smart, sustainable city with social justice.
\end{abstract}

Keywords: Strategic Planning, Public Policy, Public Management.

\section{PLANIFICACIÓN ESTRATÉGICA COMO TECNOLOGÍA SOCIAL PARA LA EFICACIA DE LA GESTIÓN PÚBLICA: UN ESTUDIO DE CASO - ITAJAÍ - SC}

\begin{abstract}
Resumen: Este artículo presenta y analiza la metodología de elaboración de la planificación estratégica de una ciudad y su importancia frente al escenario político brasileño actual. También presenta el análisis de los procesos aplicados y los resultados de una construcción de generación multisectorial con más de 3.000 personas involucradas, lo que resulta en un mapa estratégico donde se definieron los objetivos estratégicos de diferentes áreas y se crearon acciones estratégicas, con el objetivo de la construcción, en dos décadas de una ciudad inteligente, sostenible y socialmente justa.
\end{abstract}

Palabras claves: Planificación estratégica, políticas públicas, gestión pública.

Submetido em: 27/08/2019.

Aceito em: 27/09/2019.

\section{INTRODUÇÃO}

Desde o início da civilização o ser humano se agrupa em comunidades para conseguir, na essência da vida, sobreviver. As pessoas do presente século, não esperam apenas isso, mas sim construir uma sociedade que atenda a todos os anseios do mundo moderno, tais como: segurança, saúde, emprego e renda, infraestrutura, educação e bem-estar social para toda a população.

Portanto, o desafio de todo o gestor público é entender e atender as necessidades dos munícipes, criando uma forma de gerenciamento eficiente e eficaz, buscando resolver os desafios que se constituem as cidades. 
No atual momento vivenciam-se profundas transformações, o que exige do poder público plena capacidade de tomada de decisão com base em planejamento, uma vez que olhar meramente o presente responde a apenas uma parte do desafio. A outra parte, o futuro, deve ser previsto, planejado e executado a partir do momento atual, preferencialmente de forma participativa, colaborativa e transparente. O planejamento estratégico é indispensável a qualquer gestor, seja ele do setor público ou privado.

Por sua vez, o planejamento estratégico municipal constitui-se num instrumento de gerenciamento que tem o propósito de tornar a gestão de uma cidade mais eficiente, articulando políticas federais, estaduais e municipais para produzir resultados e gerar qualidade de vida adequada aos seus cidadãos.

A execução de projetos gestados no planejamento estratégico em municípios é um processo dinâmico, sistêmico, participativo e contínuo. Tem como foco a determinação dos objetivos, estratégias e ações que visem a concretização de um futuro promissor para a sociedade a que se destina. Por meio de um projeto global que considera as múltiplas temáticas da esfera municipal, valoriza a forma participativa e contínua de pensar e guiar o Município para o futuro - de forma sustentável e efetiva.

Destarte, esta é a motivação e o sentido do planejamento estratégico do Município catarinense em estudo: construir uma visão de futuro para a cidade que seja comum para todos, de forma a transformar as dificuldades em desafios, apontando as ações que irão tornar visão em realidade, numa cidade inteligente, sustentável e com justiça social.

\section{CONTEXTO DO ESTUDO}

O Município de Itajaí está localizado no litoral norte do Estado de Santa Catarina e possui atualmente 212.615 habitantes (IBGE/2017). Com forte ligação com a navegação, hoje abriga um dos maiores complexos portuários do país. O Porto de Itajaí é o segundo porto brasileiro em movimentação de cargas em contêineres, é também o maior exportador de carnes congeladas do Brasil e sede internacional da segunda maior empresa do mundo do setor alimentício. Itajaí também se destaca pela pesca industrial, no turismo e esportes náuticos, na indústria naval e complexo logístico, sendo referência ainda no ensino superior com uma das maiores universidades do Estado. 
Itajaí foi o município de Santa Catarina que mais subiu no ranking nacional dos melhores para fazer negócios em 2018 - o único do Estado a crescer entre os 50 mais bem colocados do país, passando da $46^{\mathrm{a}}$ para a $36^{\mathrm{a}}$ posição. Na categoria desenvolvimento econômico, Itajaí obteve grande destaque e hoje é considerada a 9a melhor cidade do país. Os resultados foram divulgados pela revista Exame e o índice calculado pela empresa de consultoria Urban Systems.

A Administração Pública Municipal de Itajaí possui 15 Secretarias, 04 Autarquias, 04 Fundações e 01 Instituto. Ao total, são mais de 6.000 servidores públicos, com uma média salarial de R \$ 5.009,76. As três maiores Secretarias são Educação com mais de 3.600 servidores, Saúde com mais de 1.700 e Assistência Social com cerca de 240.

Em 2017, o Governo Municipal de Itajaí decidiu reinventar a forma de administrar a máquina pública, transformando-a em um sistema empreendedor, planejado, dinâmico e inovador. Assim, surgiu o Planejamento Estratégico do Município de Itajaí - o PEMI 2040, um plano de administração pública que formula metas e objetivos sólidos que devem ser cumpridos a curto, médio e longo prazo. Em termos gerais, o objetivo do PEMI é a organização gerencial para o planejamento eficiente e eficaz das ações governamentais.

O planejamento iniciou em 2017, mas pensa também nos próximos 22 anos, em uma Itajaí de 2040. O PEMI trabalha com os Objetivos de Desenvolvimento Sustentável e é baseado no tripé Cidade Inteligente, Sustentável e com Justiça Social.

O Escritório PEMI, fruto desse processo, é um suporte para a gestão e atua em consonância com as propostas resultantes das Oficinas do Futuro, ou seja, de uma ampla consulta popular descrita na metodologia do trabalho. Nele são utilizadas competências divididas em seis eixos que auxiliam, de forma centralizada, a gerência eficaz e eficiente dos projetos, programas e ações com foco no desenvolvimento planejado de Itajaí.

\section{O Planejamento Estratégico na Gestão Pública do Executivo Municipal}

A gestão pública de um município é peculiar e complexa. Peculiar por ser responsável por um universo de multisserviços e por toda a população que vive em seu território; complexa, pois deve preocupar-se com os anseios de sua população e cumprir um rito de normas e protocolos rígidos e burocráticos. O planejamento estratégico, com a metodologia aqui apresentada e neste ambiente desafiador, surge como um caminho seguro para o sucesso da administração.

O futuro é uma localização temporal naturalmente desconhecida. Sendo assim, diante das incertezas que se mesclam com as realidades do presente 
- essencialmente a aceleração das mudanças econômicas, sociais, culturais e ambientais, é fundamental prever e organizar o caminho, do ponto de partida até o cumprimento de seu objetivo, ou de sua meta. Por isso a integração do planejamento estratégico com os diversos instrumentos e canais da gestão pública municipal torna-se relevante, uma vez que ele orienta esta governança para uma administração mais assertiva e com um futuro mais seguro, se antecipando nas respostas de problemas e obstáculos.

Desse modo, podemos dizer que a gestão pública municipal, aliada ao planejamento estratégico, pode garantir aos cidadãos serviços e políticas públicas que atendam ao bem comum, às necessidades e expectativas dos habitantes de seu território. Com ele quem governa pode definir melhor a alocação dos diversos recursos disponíveis e captáveis, seja financeiro, humano, tecnológico ou material.

É fato que vivemos um tempo de estagnação composto por crises de ordem política, econômica e social. Com isso, não há lugar que não esteja passando por obstáculos diversos para gerir aquilo que lhe foi confiado através de processo eleitoral democrático. Contudo, é inteligente o gestor público que aposte em inovação, em novos jeitos de governar, que busque ouvir sua comunidade estando o mais próximo possível dela e que, sabiamente, introduza instrumentos de gestão que contribuam para o equilíbrio das receitas e despesas, bem como para o sucesso dos empreendimentos programados para aquele seu mandato.

É notório que a maioria dos gestores públicos limitam seu pensamento apenas para aquele período onde estará atuando, geralmente de quatro anos, ou seja, uma visão de curto prazo. Esta condição é, dentre outras, um grande empecilho para o sucesso do planejamento estratégico na administração pública, em particular no executivo que possui múltiplos gestores trabalhando em consonância. Isto se contrapõe a Oliveira (2004) que afirma que esse tipo de planejamento não contempla ações imediatas e operacionais, os benefícios ocorrerão no médio e longo prazo, mas de maneira racional, lógica e estruturada.

Os administradores dos governos, em sua maioria, ainda seguem uma velha política, focada na concentração do poder em poucas mãos, burocracia nos gastos do dinheiro público e com pouca ou nenhuma participação popular.

O cenário mundial atual exige que a Administração Pública se reinvente e inicie uma gestão empreendedora e estratégica, com foco não apenas em procedimentos, mas principalmente em resultados positivos. A Administração Pública estagnou, enquanto instituições privadas rapidamente se adaptaram às novas formas de gestão.

O ambiente contemporâneo exige instituições extremamente flexíveis e adaptáveis; instituições que produzam bens e serviços de alta qualidade, assegurando alta produtividade 
aos investimentos feitos. Requer instituições que respondam às necessidades dos clientes, oferecendo-lhes opções de serviços personalizados; que influenciem pela persuasão e com incentivos, sem usar comandos; que tenham, para seus empregados, uma significação e um sentido de controle, que eles as sintam como se fossem deles. Instituições que confiram poder aos cidadãos, em lugar de simplesmente servi-los. (OSBORNE; GAEBLER, 1997, p. 16)

Sendo assim, a visão estratégica dentro de um governo é uma forma de repensar e realizar o serviço público. As empresas privadas já realizaram essa mudança de paradigma, mas os governos, de modo geral, ainda exercem o poder centralizado e burocrático, sem planejamento ou visão de futuro, ou seja, genericamente empacado num maestream retrógrado, ultrapassado.

Uma nova gestão pública deve interromper o ciclo de apenas trabalhar nas falhas da administração e começar a pensar em melhorias futuras e contínuas, antecipando possíveis problemas e planejando estrategicamente suas ações.

O desafio é transformar o velho governo, burocrático e hierárquico, em um novo, este sim estratégico, com foco no cidadão e com servidores motivados. A reinvenção da gestão do serviço público é, portanto, mais que um desejo ou Plano de Governo, mas uma necessidade imediata e urgente.

Diferente de uma empresa privada em que o objetivo é vender produtos ou serviços e obter o máximo de lucro, a Administração Pública tem como meta atender à população. “A missão fundamental do governo é 'fazer o bem', não é 'fazer dinheiro"'. (Osborne e Gaebler 1997, p. 22). Portanto, nada mais natural que, ao pensar em um novo modelo de gestão pública, se perceba a necessidade em ouvir a população quanto às questões que envolvem o uso dos recursos públicos.

Ao envolver a população na tomada de decisões, o Governo não só se torna mais transparente, atraindo a confiança da opinião pública, mas responsabiliza as pessoas pelos gastos do próprio dinheiro.

\section{DESCRIÇÃO DO PEMI 2040}

Na construção do Planejamento Estratégico do Município de Itajaí (o PEMI 2040), foi provocado o envolvimento de múltiplos atores que protagonizam, nos mais diversos setores da sociedade civil organizada (o ambiente exógeno), bem como no universo da Prefeitura Municipal (o ambiente endógeno), os fundamentos para a sua consolidação.

Este ponto foi fundamental por ter sido desenvolvido de forma colaborativa. Estabeleceu-se como o ponto forte na implantação do processo, justamente por possibilitar a população, por meio de seus líderes, a oportunidade de participar 
no processo decisório relacionado ao bem comum e ao futuro da cidade. Nele algumas etapas foram fundamentais:

1. A consolidação dos 100 primeiros dias de governo, com o cumprimento de metas estabelecidas para o período e em cada unidade gestora da prefeitura.

2. A parceria entre Prefeitura Municipal e a Universidade do Vale do Itajaí, oficializada em abril de 2017.

3. A definição do escopo do trabalho, realizado desde dezembro de 2016 a junho de 2017, teve como propósito determinar e documentar a lista de objetivos específicos, entregas, tarefas, recursos, custos e prazos.

4. O Diagnóstico com os líderes executivos da Prefeitura, com a identificação no ambiente endógeno o levantamento dos pontos fortes e fracos do município de Itajaí, no âmbito da operação das secretarias, das fundações e das autarquias, num total de 272 entrevistas.

5. Formação da rede de Multiplicadores do PEMI: composta por 40 servidores, preferencialmente efetivos, os multiplicadores se constituem no elo entre o Planejamento Estratégico do Município de Itajaí (Escritório PEMI) e as unidades gestoras da Prefeitura Municipal. Eles desempenham o papel de porta-vozes e auxiliadores nas atividades relacionadas.

6. Oficinas do Futuro: num total de 08 Oficinas com a dinâmica de envolver e mobilizar a população na elaboração do PEMI 2040, reservando o direito e o dever dos munícipes de participar diretamente da discussão e da definição do destino das questões relativas ao município. Participaram 477 lideranças de todos os segmentos da sociedade organizada.

7. Rodas de conversa: reuniões que aconteceram dentro e fora do ambiente da prefeitura. Nestes encontros foram envolvidas mais de 1.000 pessoas com o propósito de apresentar e discutir a nova proposta de gestão aliada ao planejamento estratégico. Elas aconteceram em sedes de entidades de classe, como associações e sindicatos, assim como dentro das secretarias, fundações e autarquias do município. Somente no âmbito da Secretaria Municipal de Educação, por exemplo, as Rodas de Conversa reuniram um público de 700 pessoas, composto por gestores e representantes de pais de alunos de todas as escolas da rede municipal de educação.

8. Pesquisa Social com os munícipes: desenvolvida pelo Instituto de Pesquisas Sociais da Univali, atingindo 1139 cidadãos em 28 bairros, com o intuito de identificar a percepção (o olhar) da população quanto ao município e à gestão municipal.

9. Construção de instrumentos auxiliadores na aplicação e monitoramento do PEMI - mecanismos criados e utilizados para a garantia do funcionamento eficaz e responsável, idealizados com a proposta de serem transparentes e colaborativos, 
tais como: a instituição de um comitê de decisões e de um Conselho Consultivo composto por 23 membros de segmentos distintos do município, o sistema de indicadores de gestão e o sistema de indicadores desenvolvimento sustentável baseado nos ODS, o banco de projetos aliado ao monitoramento de janelas de oportunidades para captação de recursos, o controle de contratos e a prestação de contas, a contínua relação com a comunidade e suas lideranças e uma ferramenta de gestão e monitoramento de projetos, o DataPEMI, desenvolvido em parceria com a Secretaria Municipal de Tecnologia, são exemplos.

10. Implantação do Escritório PEMI: a partir dos princípios de Gestão de Projetos, o escritório de gestão PEMI foi criado para ser o órgão de apoio às secretarias, autarquias e fundações do Município de Itajaí, com o objetivo de promover a sinergia entre estes órgãos, e facilitar a execução das ações identificadas, com método e procedimento definido, de forma a evidenciar o sucesso na atuação.

Dentre as atribuições, pode-se destacar: o mapeamento dos projetos atuais em execução pelo Município de Itajaí; o apoio no desenvolvimento de projetos a partir do PEMI 2040 e do plano plurianual (PPA); o monitoramento das janelas de oportunidades para a proposição de projetos junto ao governo estadual, federal, órgãos de apoio e fomento ao desenvolvimento de programas e políticas públicas.

Em relação às técnicas de coleta de dados, a pesquisa contou com a observação participante dos autores, bem como, a pesquisa realizada foi de natureza qualitativa e descritiva e também se utilizou o documento final do planejamento estratégico realizado, como base.

A observação participante foi praticada na instituição gestora do projeto e ocorreu a partir da concepção do projeto até os dias atuais, o que propiciou ter amplo conhecimento do projeto. Marconi e Lakatos (2009) afirmam que a observação participante tem como base a participação real do pesquisador com o grupo alvo da pesquisa, onde o pesquisador se envolve com o grupo que está sendo estudado e acaba participando das atividades cotidianas deste.

Para alcançar o objetivo da pesquisa e pelo aspecto do objeto de análise, optou-se por uma abordagem qualitativa, a qual busca entender situações singulares como parte de um contexto único e suas interações e é ricamente descritiva, uma vez que enfocam em processos, sentidos e experiências (MERRIAM, 1998).

Para a análise de dados, teve-se como objetivo resumir com qualidade as informações adquiridas por meio da observação participante e pelos documentos do planejamento estratégico de modo a viabilizar a exposição das informações pertinentes e relevantes a esta pesquisa. 


\section{Os Objetivos de Desenvolvimento Sustentável e o PEMI 2040}

Na estruturação e implantação do PEMI 2040 foi considerada a relevância mundial da Agenda 2030, proposta no ano de 2015 pela Organização das Nações Unidas (ONU) e que instituiu os 17 Objetivos de Desenvolvimento Sustentável (ODS).

Neste contexto o município de Itajaí possui um forte envolvimento com as questões relativas à sustentabilidade e à justiça social, que são a base dos ODS. Tal compreensão ocorre desde os Objetivos de Desenvolvimento do Milênio (ODM), sendo que ainda em 2005, por exemplo, implementou-se o Selo Social de Itajaí, uma estratégia que certifica, dá reconhecimento e propagação às iniciativas de organizações públicas e privadas da sociedade civil organizada, bem como de pessoas físicas, que realizam investimentos sociais e geram resultados, internos e externos, em consonância com os ODS. O Selo Social de Itajaí foi instituído, posteriormente, como programa do município, pela Lei № 5403, de 11 de novembro de 2009.

Diante disso, e com olhar atento ao Pacto Global das Nações Unidas, foi criada no ambiente do PEMI uma competência que trata exclusivamente dos ODS, sendo ela que administra o Sistema de Indicadores de Desenvolvimento Sustentável do Município de Itajaí. Tal eixo de trabalho estabelece a relação do escritório PEMI, no contexto dos ODS, com as unidades gestoras da prefeitura, faz a coleta e o tratamento dos dados produzidos e informa aos setores competentes sobre os indicadores apurados, sua evolução, pontos críticos e positivos, entre outros.

A iniciativa de aliar os ODS ao planejamento estratégico se deu com o pensamento focado na transformação de Itajaí numa "Cidade Inteligente, Sustentável e com Justiça Social", ela provoca todos os diretamente envolvidos, e de modo geral também a população, a dar importância para o futuro e para um processo de reflexão com responsabilidade sobre o que vem depois, ou seja, suscitar uma prática intensa de integridade e humanidade.

Tal como Ignacy Sachs, polonês e cidadão do mundo, considerado a maior autoridade na área, define sustentabilidade como um desenvolvimento socialmente includente, politicamente descentralizado, ambientalmente prudente e economicamente sustentado no tempo. Além disso, este desenvolvimento precisa ter a capacidade de satisfazer as necessidades presentes, sem comprometer a possibilidade das gerações futuras de suprir suas próprias necessidades (Relatório de Brundtland, Nosso Futuro Comum, 1987).

No quadro abaixo apresenta-se a correlação dos objetivos do PEMI 2040 com os ODS. 


\section{Dimensão EConômICA}

Desenvolver a gestão e novas tecnologias para a pesca artesanal.

Potencializar a pesca industrial.

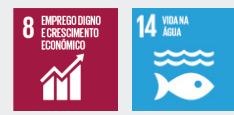

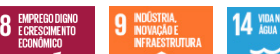

T1

Fomentar as atividades agropecuárias do município e promover a expansão urbana sustentável nas comunidades rurais.

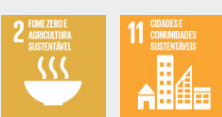

Ampliar as atividades turísticas.

Desenvolver a operação do

Distrito de Inovação.
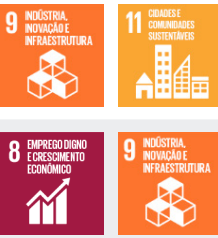

Fomentar o crescimento econômico da indústria, do comércio e do serviço.
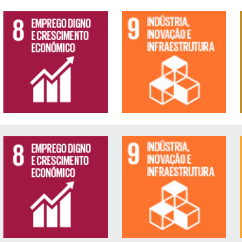

Aperfeiçoar a gestão portuária.

\section{DIMENSÃo SOCIAL}

Fomentar oportunidades de trabalho e renda para a população.

Ampliar e qualificar os programas esportivos e de lazer.

Potencializar a cultura na formação da sociedade itajaiense.

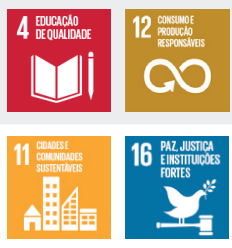

segurança do munícipio.
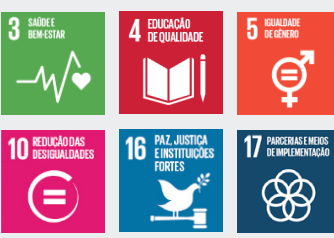

Aprimorar os serviços de saúde na prevenção de doenças.

Proporcionar saúde de qualidade para todos.

Garantir a educação para todos. 
Desenvolver a qualificação da educação em todos os níveis.

Ampliar as políticas e as práticas habitacionais.

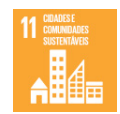

\section{Dimensão Infraestrutura e Meio Ambiente}

Implementar plano de mobilidade urbana.

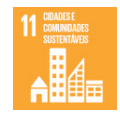

Assegurar a preservação ambiental dos rios Itajaí Açu e Itajaí Mirim.
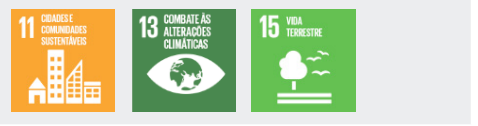

Tornar perene as práticas de preservação ambiental.
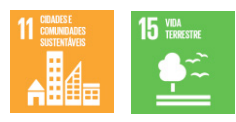

Viabilizar o tratamento de $100 \%$ do lixo reciclável e orgânico gerado.

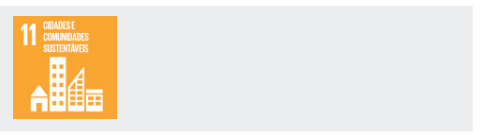

Ampliar e modernizar a infraestrutura da cidade.

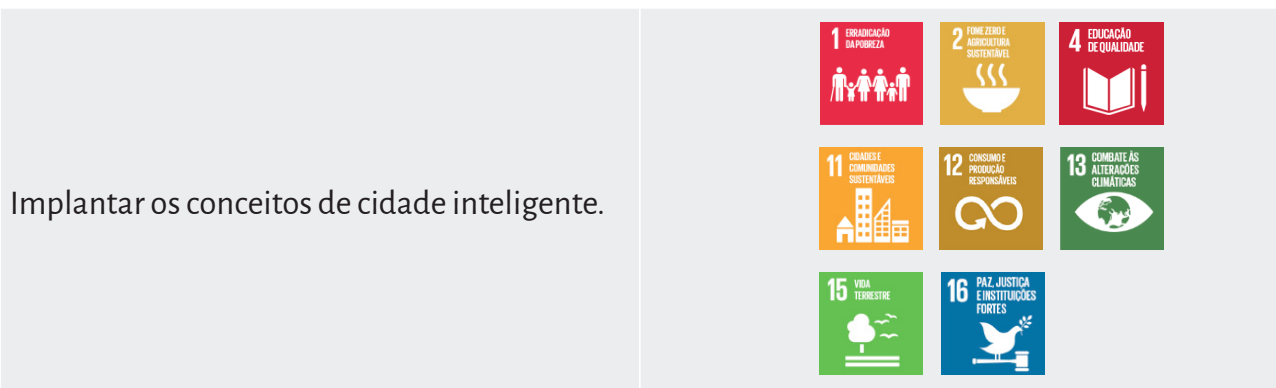

Humanizar os espaços públicos.

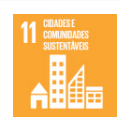

\section{Dimensão GovernançA}

Aprimorar a eficiência do serviço público.

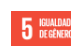

Desenvolver políticas de atenção aos servidores.

Garantir segurança jurídica para o município.

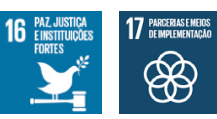

Promover a eficiência dos processos de suprimentos.

Aprimorar o atendimento e comunicação com o cidadão. 


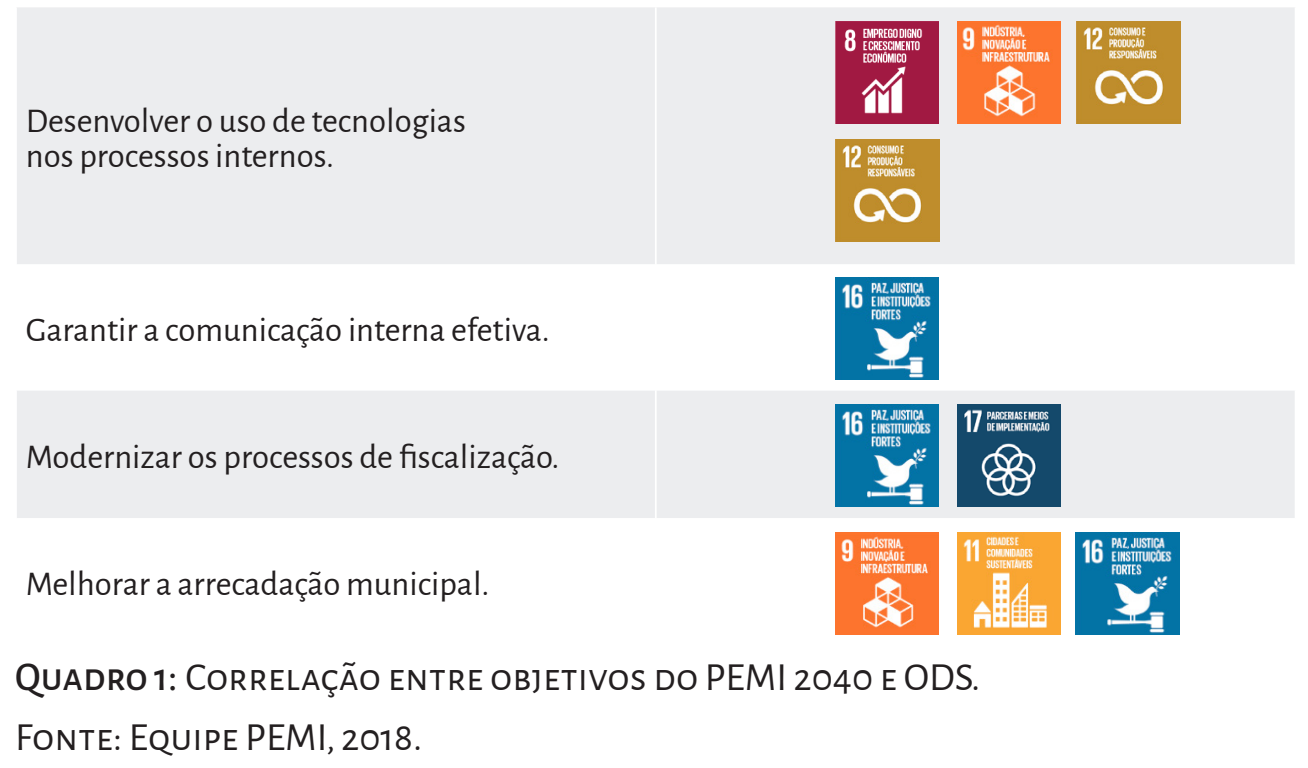

\section{PRINCIPAIS RESULTADOS (A CURTO PRAZO)}

Conforme apresentado, para a realização do planejamento estratégico se faz necessário o envolvimento de todas as partes interessadas, e isso justifica a estrutura metodológica apresentada na seção anterior, que tem seu valor reforçado ao analisar os resultados obtidos. Esta metodologia proporcionou grande fundamentação para a definição da missão, visão, valores, metas, objetivos estratégicos, ações estratégicas e os indicadores de gestão justamente por envolver, em suas dimensões, todo o Município.

O diagnóstico aplicado na prefeitura do Município permitiu conhecer os processos realizados por cada secretaria, que por meio da análise dos resultados obtidos pode-se identificar as forças, fraquezas, oportunidades e ameaças. Este processo envolveu diversos servidores públicos que contribuíram expondo suas atividades, experiências e conhecimento práticos sobre as atividades realizadas em suas respectivas secretarias.

A pesquisa social realizada nos bairros, teve como objetivo principal identificar qual a expectativa da sociedade quanto ao futuro de Itajaí. Basicamente, por meio de um questionário elaborado com foco nos objetivos e resultados esperados, buscou-se conhecer o que os munícipes esperam da cidade em que vivem para as próximas duas décadas. Esta pesquisa apontou que 25\% (vinte e cinco) dos entrevistados definiram como problema principal a segurança e, portanto, como expectativa pensam em uma cidade mais segura. Cerca de 18\% (dezoito) sinalizaram o interesse em infraestrutura e mobilidade urbana como sendo sua 
principal expectativa de melhoria. Para saúde e gestão pública, somente 3\% (três) têm expectativas relacionadas a estas áreas.

Nas tendências e boas práticas foram identificadas 101 (cento e uma) proposições, e destas houve alguns destaques, como principalmente a necessidade de um novo modelo de governança pública, o uso de alta tecnologia e seu emprego para a melhoria da educação, saúde e segurança. Também se percebeu uma forte tendência para a humanização das cidades, criando áreas verdes para o convívio social e revitalização de ruas e rios, estes que também já são boas práticas realizadas por diversas cidades nacionais e internacionais. A pesquisa de tendências também demonstrou um aumento com a preocupação na conservação ambiental, redução da vulnerabilidade social e imigrações desordenadas. Apontou a propensão do compartilhamento de meios de transporte e moradias, além de uma mudança nas relações de trabalho.

As Oficinas do Futuro foram realizadas em 8 (oito) etapas, sendo que em cada uma houve a participação de diversas partes interessadas ao planejamento estratégico, como representantes de empresas e bairros (urbanos e rurais), ONGs e grupos étnicos, instituições de ensino, sindicato e associações, instituições sociais, políticas, religiosas, imprensa e jovens, todos com o propósito de idealizar a Itajaí de 2040. Como resultado destas oficinas obtiveram-se 1188 (mil cento e oitenta e oito) ideias relacionadas à cidade do futuro.

Como efeito dos trabalhos realizados, definiu-se o Mapa Estratégico do Município conforme apresenta a Figura 1. O referencial apresenta as relações entre a visão, missão e valores com as premissas, dimensões e áreas estratégicas, objetivos e ações estratégicas e as metas e indicadores.

\begin{tabular}{|c|c|c|c|}
\hline \multicolumn{4}{|c|}{ MAPA ESTRATÉGICO - PEMI 2040} \\
\hline \multicolumn{4}{|c|}{ D I P T O : Diagnóstico + Cidade em números + Pesquisa nos bairros + Tendências e boas práticas + Oficinas do futuro } \\
\hline VISÃO & \multicolumn{2}{|c|}{ MISSÃo } & VALORES \\
\hline \multicolumn{4}{|c|}{$\begin{array}{l}\text { PREMISSAS (5): Município Inteligente, Inovador e Atrativo - Justiça Social, Inclusivo e Próspero - Sustentável, Planejado e } \\
\text { Integrado - Saudável com Qualidade de Vida - Excelência em Educação }\end{array}$} \\
\hline DIMENSÃO 1: Econômica & $\begin{array}{c}\text { DIMENSÃO 2: } \\
\text { Desenvolvimento Social }\end{array}$ & $\begin{array}{c}\text { DIMENSÃO 3: } \\
\text { Infra e Meio Ambiente }\end{array}$ & $\begin{array}{l}\text { DIMENSÃO 4: } \\
\text { Governança }\end{array}$ \\
\hline $\begin{array}{l}\text { ÁREAS ESTRATÉGICAS: } \\
\text { Indústria e Serviços } \\
\text { Ciência e Tecnologia } \\
\text { Agricultura e Pesca } \\
\text { Porto e Turismo }\end{array}$ & $\begin{array}{l}\text { ÁREAS ESTRATÉGICAS: } \\
\text { Educação e Cultura } \\
\text { Saúde E Segurança } \\
\text { Social e Esporte } \\
\text { Trabalho e Habitação }\end{array}$ & $\begin{array}{c}\text { ÁREAS ESTRATÉGICAS: } \\
\text { Infraestrutura } \\
\text { Meio Ambiente } \\
\text { Urbanismo } \\
\text { Mobilidade Urbana }\end{array}$ & $\begin{array}{c}\text { ÁREAS ESTRATÉGICAS: } \\
\text { Finanças } \\
\text { Processos e Pessoal } \\
\text { Planejamento } \\
\text { Jurídico }\end{array}$ \\
\hline $\begin{array}{l}\text { OBJETIVOS } \\
\text { ESTRATÉ́GICOS }\end{array}$ & $\begin{array}{c}\text { OBJETIVOS } \\
\text { ESTRATÉGICOS }\end{array}$ & $\begin{array}{c}\text { OBJETIVOS } \\
\text { ESTRATÉGICOS }\end{array}$ & OBJETIVOS ESTRATÉGICOS \\
\hline AÇÕES ESTRATÉGICAS & AÇÕES ESTRATÉGICAS & AÇÕES ESTRATÉGICAS & AÇÕES ESTRATÉGICAS \\
\hline METAS E INDICADORES & METAS e INDICADORES & METAS E INDICADORES & METAS E INDICADORES \\
\hline
\end{tabular}

Figura 1: DoCUMENTAÇÃo D I P T O. FONTE: AUTORES (2017). 
As premissas são o ponto de partida para o planejamento e servem como modelo construtivo para as iniciativas que nortearão o seu desenvolvimento. Enquanto que as dimensões são consideradas a representação de agrupamentos das áreas de atuação que possuem elevada relevância e que concatenam o conjunto de ações com objetivos em comum, sendo desdobradas em áreas que, em tese, deverão ser impactadas pelo conjunto de objetivos e ações do planejamento estratégico, originando as áreas estratégicas.

Já os objetivos estratégicos são os resultados a serem alcançados pelo conjunto de atividades executadas no intuito de se obter êxito no cumprimento do planejamento estratégico, ao passo que as ações estratégicas se caracterizam como os meios para o sucesso dos objetivos estratégicos e que poderão se transformar em projetos ou então em planos de ação.

Definidas também as metas, que são pontos ou posições a serem alcançados no futuro. Elas se constituem em propulsores da gestão - gerenciar consiste em desenvolver ações objetivando o atingimento das metas e para medir a evolução dos resultados obtidos com a implantação das ações, de forma que, ao se comparar resultados com as metas pré-estabelecidas, se obtêm os indicadores de gestão.

\section{CONSIDERAÇÕES FINAIS}

O Planejamento Estratégico do Município de Itajaí, o PEMI 2040, está pautado no objetivo de desenvolver a modernização da gestão do município de Itajaí, com a adoção da inter-relação de ações, quer sejam gerenciais, quer sejam dos ODS, entre as secretarias municipais de governo. Ele pretende ainda operar o gerenciamento de forma pontual das ações e dos projetos em andamento, buscando oportunidades de novos projetos e programas. Consideram-se esses como os objetivos explícitos, mas se tem também o grande objetivo implícito de que, ao longo da execução, aconteça a grande mudança cultural dos paradigmas de gestão existentes no local.

Destaca-se, ainda que, a partir das ações estratégicas, o escritório PEMI de gestão atuará junto às secretarias, às autarquias e às fundações municipais, apoiando na definição de programas e projetos, a priorização destes, a definição de metas e os indicadores de avaliação.

Ao concluir um projeto de tamanha dimensão e amplitude, com o conjunto de procedimentos desenvolvidos, pode-se dizer que se conhece um pouco mais da operação administrativa e técnica do Município de Itajaí. Bem como é viva entre a equipe a crença de se ter dado o passo inicial no caminho para tornar realidade o que se preconizou como um município: inovador e atrativo; com justiça social, 
inclusivo e próspero; sustentável, planejado e integrado; saudável, com qualidade de vida e com excelência em educação.

Devido ao atual cenário brasileiro, fortemente influenciado pela recessão, e principalmente pela globalização e aumento na competitividade, exige das organizações novas formas de agir, de modo que garanta a sua sobrevivência futura. Neste contexto, e influenciado em especial pela nova tendência de gestão pública, o Município em estudo buscou realizar o planejamento estratégico para as próximas duas décadas, de modo que permita a ele prosperar em um futuro que não pode ser previsto.

Em virtude da complexidade de se realizar um planejamento estratégico para uma cidade, fez-se necessário adotar uma metodologia que atendesse as necessidades de tal projeto. Esta metodologia, apresentada neste artigo, proporcionou um forte embasamento para a definição da visão, missão, valores, metas e objetivos estratégicos do Município, justamente por envolver representantes de todas as partes interessadas e processos inovadores.

Como resultado geral do projeto de planejamento estratégico foram envolvidas aproximadamente $\mathbf{3 . 0 0 0}$ (três mil) pessoas, sendo 272 (duzentos e setenta e duas) no diagnóstico realizado na prefeitura, 1.139 (mil cento e trinta e nove) munícipes entrevistados na pesquisa realizada em 28 (vinte e oito) bairros, mais de 1.000 indivíduos foram reunidos nas Rodas de Conversa e 477 (quatrocentos e setenta e sete) líderes comunitários colaboraram e foram ouvidos nas oficinas do futuro.

Como efeito do mapa estratégico definiram-se 33 (trinta e três) objetivos estratégicos que atuam em 24 (vinte e quatro) áreas distintas e originam 228 (duzentos e vinte e oito) ações estratégicas, as quais serão responsáveis pela criação de diversos projetos que visam atender suas necessidades. Para o monitoramento do desempenho destes resultados, definiu-se $\mathbf{8 0}$ indicadores de gestão, supridos principalmente pelo fruto do documento Itajaí em Números.

O PEMI 2040 viabilizou e pretende manter a articulação e coordenação de políticas públicas, de planejamento, de inovação, e de capacitação, que já alavancou investimentos nacionais na ordem de mais $\mathrm{R} \$ 326$ milhões e estrangeiros, na ordem de U\$ 62,5 milhões, nos últimos dois anos.

Neste sentido, analisando os resultados obtidos, pode-se perceber a relevância da metodologia aplicada e a importância deste estudo como base para outros trabalhos em municípios que ainda em 2018, não possuíam um planejamento para o direcionamento da gestão pública. 


\section{REFERENNCIAS}

CASTRO, Rodrigo Batista de. Eficácia, eficiência e efetividade na administração pública. 2006.

CATELLI, Armando; SANTOS, Edilene Santana. Mensurando a criação de valor na gestão pública. Revista de Administração Pública, v. 38, n. 3, p. 423-450, 2004.

CHIAVENATO, Idalberto; SAPIRO, Arão. Planejamento estratégico: Fundamentos e aplicações, 2 Ed. Rio de Janeiro, Elsevier, 2010.

COSTA, A. P. P. Balanced Scorecard: conceitos e guias de implementação. São Paulo: Atlas, 2006.

DA SILVA JUNIOR, Sady Darcy; LUCIANO, Edimara Mezzomo. Proposta de mapa estratégico sob a perspectiva dos fatores críticos para a maturidade em gestão de projetos. Revista Gestão e Projetos-GeP, v. 1, n. 1, p. 26-46, 2010.

DENHARDT, Janet Vinzant; DENHARDT, Robert B. The new public service: Serving, not steering. ME Sharpe, 2007.

DRUCKER, Peter F. Introdução à administração. Tradução Carlos A. Malferrari São Paulo: Pioneira, 1984.

FERNANDES, Amarildo da Cruz. Mapas estratégicos do Balance Scorecard: contribuições ao seu desenvolvimento. 2002.

IPS - Instituto de Pesquisas Sociais Univali. Relatório de resultados de pesquisa para o PEMI Itajaí 2040. Universidade do Vale do Itajaí. Itajaí, julho. 2017.

KAPLAN, R. S.; NORTON, D. P. Mapas estratégicos - Balanced Scorecard: convertendo ativos intangíveis em resultados tangíveis. (10a. ed., p. 10) Rio de Janeiro: Elsevier (2004).

MARCONI, M.A.; LAKATOS, E.M. Metodologia do trabalho científico. 7. ed. São Paulo: Atlas, 2009. 
MERRIAM, S.B. Pesquisa Qualitativa e Aplicações de Estudo de Caso na Educação. Jossey-Bass Publishers, 350 Sansome St, São Francisco, CA 94104, 1998.

MOTTA, Paulo Roberto de Mendonça. O estado da arte da gestão pública. Revista de Administração de Empresas, v. 53, n. 1, p. 82-90, 2013.

NOSSO FUTURO COMUM (Relatório de Brundtland). Comissão Mundial sobre o Meio Ambiente e Desenvolvimento. Rio de Janeiro: Editora da Fundação Getúlio Vergas, 1998.

NASCIMENTO, Edson Ronaldo. Gestão Pública: gestão pública aplicada: União, Estados e Municípios, gestão pública no Brasil, de JK à Lula, gestão orçamentária e financeira, a gestão fiscal responsável, tributação e orçamento, tópicos especiais em contabilidade pública, gestão das contas nacionais, gestão ecológica e ambiental. 2 ed. São Paulo: Saraiva, 2010.

NAÇÕES UNIDAS, 2017. 17 Objetivos de Desenvolvimento Sustentável. Disponível em: https://nacoesunidas.org/conheca-os-novos-17-objetivos-de-desenvolvimento-sustentavel-da-onu/. Acesso em: mar. 2018.

OLIVEIRA, Djalma Pinho Rebouças. Planejamento Estratégico: Conceitos, metodologia e práticas - 20. ed. São Paulo: Atlas, 2004.

OSBORNE, David; GAEBLER, Ted. Reinventando o governo: como o espírito empreendedor está transformando o setor público. Brasília, DF: MH Comunicação, 1997.

OSBORNE, David; GAEBLER, Ted. Reinventando o governo: como o espírito empreendedor está transformando o setor público. Mh Comunicação, 1994.

RUMELT, Richard P. Good Strategy / Bad Strategy. [S.l.]: Crown Business. 2011.

SANDERSON, Ian. Performance management, evaluation and learning in 'modern'local government. Public administration, v. 79, n. 2, p. 297-313, 2001. 
SANTOS, Paloma Maria; SELIG, Paulo Maurício. Indicadores para o novo serviço público: uma análise bibliométrica e sistêmica. Perspectivas em Ciência da Informação, v. 19, n. 3, p. 82-97, 2014.

SARKER, Abu Elias. New public management in developing countries: An analysis of success and failure with particular reference to Singapore and Bangladesh. International Journal of Public Sector Management, v. 19, n. 2, p. 180-203, 2006.

SEBRAE - MICRO, SERVIÇO BRASILEIRO DE APOIO A MICRO E PEQUENAS EMPRESAS. Santa Catarina em números: macrorregião sul. 2010.

VIEIRA, Ronan Domingues. As normas brasileiras de contabilidade aplicadas ao setor público e os demonstrativos contábeis na avaliação de desempenho da gestão pública municipal: os casos de Jumirim e Laranjal Paulista/SP. 2014. 